\title{
Knowledge and Attitude towards HIV/AIDS among transsexuals in Kuantan, Pahang
}

\author{
Samsul $D^{a}$, Razman $M R^{b}$, Ramli $M^{c}$, Mohd Aznan $M A^{a}$, Maliya $S^{a}$, Muhamad Shaiful Lizam $M A^{a}$, Muhammad \\ Salman $\mathrm{MH}^{\mathrm{a}}$, Mohamad Faqihuddin $\mathrm{H}^{\mathrm{a}}$ \\ ${ }^{a}$ Department of Family Medicine, Kulliyyah of Medicine, International Islamic University Malaysia, \\ ${ }^{b}$ Department of Community Medicine, Kulliyyah of Medicine, International Islamic University Malaysia, \\ 'Department of Psychiatry, Kulliyyah of Medicine, International Islamic University Malaysia,
}

\begin{abstract}
Introduction: Lack of knowledge and negative attitude towards HIV/AIDS may be the risk factors for HIV infection among transsexuals. Research on knowledge and attitude towards HIV infection in transsexual communities is very limited at both local and international levels. This study aimed to assess the knowledge and attitude towards HIV infection among the male-to-female transsexual community in Kuantan, Pahang. Methods: A cross-sectional study was carried out from July to August 2014 among 33 male-to-female transsexuals in Kuantan, Pahang. Convenience sampling was used. Participants who gave consent answered a self-administered questionnaire. Data obtained was analyzed with descriptive statistics, $\mathrm{x}^{2}$-test, and independent sample t test. Results: The majority of the subjects in this study were 29 years and below (48.5\%), Muslims (93.9\%), and had completed up to secondary education (60.6\%). Most of them were sex workers $(60.6 \%$ ), and had relatively low income (no income to RM 3000 , mean of RM1528). A total of $87.9 \%$ of the subjects demonstrated good knowledge and also positive attitude towards HIV/AIDS. Level of education was significantly associated with scores in knowledge $(p=0.01)$. Conclusions: Despite the positive outcome from this study, misconceptions towards HIV/AIDS still exist among transsexuals. Education and interventions from multiple directions on HIV/AIDS are essential to deliver the correct information to this population, so as to emphasize prevention, early detection, and holistic medical care. Transsexuals also require attention from religious bodies and non-governmental organizations to help them in employment, financial, spiritual, and psycho-social issues.
\end{abstract}

\section{KEYWORDS: Transsexualism, HIV, Acquired Immunodeficiency Syndrome, Sex workers}

\section{INTRODUCTION}

The first case of HIV in Malaysia was reported in 1986. Within 28 years, the cumulative number of reported HIV infection had reached 101,672. The estimated number of people living with HIV infection by the end of 2013 was 86,324, and in 2013 alone, the number of reported cases of newly diagnosed HIV infection was 3,393 . In this country with a total population of slightly less than 29 million, HIV had become epidemic. In the early phase, the epidemic was driven by injecting drug users. Since 1994, the trend of HIV transmission began to shift towards sexual

Corresponding author:

Samsul Draman

Department of Family Medicine

Kulliyyah of Medicine

International Islamic University Malaysia

25150 Indera Mahkota

Kuantan, Pahang

Malaysia

Tel no :+6013-9827277 (mobile)

$+609-5704572$ (office)

Fax no: +609-5716542 (fax)

Email : nurin@iium.edu.my transmission. The transsexuals were regarded as one of the most-at-risk populations. ${ }^{1}$

The term transsexual, or transgender, refers to individuals who experience persistent and distressing discomfort with their biological sex, and wish to live as the opposite sex from which they have been born. ${ }^{2-4}$ They are labelled as sexual deviants and are generally discriminated against by society in Malaysia and also other parts of the world. ${ }^{2,4,5}$ This stigma leads to severe difficulties in employment and access to healthcare. ${ }^{1-3,5,6}$ Studies in Malaysia showed that more than $80 \%$ of them ended up in the sex trade. ${ }^{1,2}$ From the nationwide Integrated Bio-Behavioural Surveillance (IBBS) studies carried out by the Malaysian Ministry of Health in 2012, many of the transsexuals engage in activities that put them at high risk for HIV infection, and HIV prevalence among transsexuals alone was $5.7 \%{ }^{1}$

Lack of knowledge and negative attitude regarding HIV/AIDS are risk factors for HIV infection among transsexuals and other populations. ${ }^{7-9}$ There is very limited research and data on the transsexual population when it comes to evaluation of HIV/AIDS 
education programs ${ }^{5}$. This study was carried out to describe the socio-demographic profile among male-to-female-transsexuals in Kuantan, to identify their main sources of information on HIV/AIDS, and to assess their knowledge and attitude towards HIV/AIDS. By relating this study, it was hoped that HIV-related problems in this community could be identified and addressed, so that holistic policy and programs could be developed for this population for better care.

\section{MATERIALS AND METHODS}

A cross-sectional study was carried out in four areas of Kuantan (Jalan Gambut, Jalan Pasar Baru, Jalan Dato Wong Ah Jang and Jalan Mat Kilau), where the transsexual communities appear and gather most frequently in Kuantan. These four areas were identified by one of the authors who was well acquainted with the transsexual communities in Kuantan. Thus, these four areas were taken to be representative of the entire town. The study period took seven weeks from July to August, 2014. The research protocol was approved by IIUM Research Ethics Committee.

The study population consists of all male-to-female transsexuals in the mentioned four areas in Kuantan, who could understand English or Malay language. The initially calculated sample size was 385 , with a precision of $5 \%$. The transsexuals were approached face-to-face in these four areas, and were explained the purpose and procedure of this study. However, only 33 subjects gave consent for participation.

An anonymous and self-administered questionnaire, known as the Development and Psychometric Evaluation of Brief HIV Knowledge Questionnaire (HIV-KQ-18), ${ }^{10}$ was used. It was translated into Malay language and obtained a Cronbach's alpha of 0.70 , after being validated by a pilot study performed on five transsexuals who were not included as subjects in this study. The questionnaire consists of five parts: 1) sociodemographic information, 2) knowledge on HIV/AIDS, 3) attitude towards HIV/AIDS, 4) source of information on HIV/AIDS, and 5) self-reported information on HIV testing and HIV status. Scorings were used when assessing the knowledge and attitude towards HIV/AIDS.

The level of knowledge and attitude were classified into "good" or "poor" with the cut-off point of $50 \%$ obtained from the scoring system. Data analysis was then done with the Statistical Package for Social Sciences Software (SPSS) version 19. Statistical significance was set to be $p<0.05$. Descriptive statistics, $x^{2}$-test, and independent sample $t$ test were used.

\section{RESULTS}

The mean age among the transsexuals was $35.15 \pm$ 10.62 years, where most of them $(48.5 \%)$ were 29 years and below, $21.2 \%$ of them were between 30 to 39 years, and $30.3 \%$ of them were 40 years and above. Most $(60.6 \%)$ of the subjects were sex workers, the rest of the subjects had some skills $(27.3 \%)$, or were doing labor work $(3.0 \%)$, or were unemployed (9.1\%). Majority (93.9\%) were Muslims, the rest were Christian (3.0\%) and Hindu (3.0\%). Education levels varied from up to tertiary (21.2\%), secondary $(60.6 \%)$, primary $(12.1 \%)$, or none at all (6.1\%). Among all the 33 subjects, 3 (9.1\%) had no income at all. For the other 30 subjects, their monthly income ranged between RM200 to RM3000, with a mean of RM1528. 15.2\% of them earned less than RM1000 monthly, 24.2\% earned between RM1000 to RM2000, while 51.5\% of them earned more than RM2000 a month.

The main sources of information on HIV/AIDS were "friends" (75.8\%), "health officers" (75.8\%), "television" (72.7\%), followed by "newspapers" (63.6\%), “non-government organization” (54.5\%), and "internet" (51.5\%). Others were "radio" (48.5\%), "posters and pamphlets" (39.4\%), "teachers" (33.3\%), "family members" (24.2\%), and "others" such as magazines and books (30.3\%).

Among the 33 subjects, 29 (87.9\%) of them have had HIV status tested within the last 5 years, out of which only one of them was tested for HIV within the past one year. Among these 29 subjects, 2 were HIV positive, one of whom reported to have been on anti-retroviral therapy; 4 of them claimed to be HIV negative, while $81.8 \%$ of them were unsure. Places where HIV infection was tested were private clinics (34.4\%), government health clinics $(24.1 \%)$, hospitals (17.2\%), pharmacy (3.4\%), and drug intervention centers $(20.7 \%)$.

Only 4 subjects answered all questions correctly. As shown in table 1 , questions on knowledge about mode of transmission through sexual means (questions 4, 11, 14, 17) were answered correctly by $67.7 \%$ to $84.8 \%$ of the subjects. Otherwise, $63.7 \%$ of the subjects did not know that withdrawal of penis before climax cannot prevent HIV infection, and only $30.3 \%$ knew that natural skin condoms do not work better than latex condoms against HIV. From table $2,97 \%$ of the subjects were willing to use condoms, and $90.9 \%$ of them were willing to accept free condoms. Majority $(81.8 \%)$ of them were willing to volunteer for HIV screening test.

Among the subjects, $87.9 \%$ demonstrated good level of knowledge and attitude towards HIV/AIDS. Age, occupation, income, religion and education level were analyzed against level of knowledge and attitude towards HIV/AIDS (Table 3). Only level of education was significantly associated with level of knowledge on HIV/AIDS ( $p=0.01)$. 


\section{DISCUSSION}

Age distribution in this study was similar to a study in Thailand, where the majority of the subjects were below 29 years. ${ }^{11}$ However, in another study in Malaysia, the subjects were all older than 30 years ${ }^{4}$. Such a large proportion of transsexuals engaging in sex trade at the prime of their life strongly suggested this was a result of social discrimination, financial vulnerability, and difficulties in finding employment. $^{12}$

Education levels were found to be similar to previous studies, where majority of them had completed secondary education. ${ }^{4,11}$ Hence, enforcing education on HIV/AIDS in secondary schools could maximize the impact. Besides, it is also thought that transsexuals with higher education levels were more capable of educating themselves by proactively seeking information on HIV/AIDS from multiple sources, and were also more capable of understanding the information they obtained.

Muslims comprised the majority of the study population, similar to previous studies in Malaysia. ${ }^{2,4}$

Most of the subjects in this study were sex workers, while in another study in Kuala Lumpur, only $25 \%$ of them sold sex, the rest were unemployed or had some part time jobs. However, it is suspected that the prevalence of sex workers was under-reported in the study mentioned.

In contrast to the same study in Kuala Lumpur, where more than half of the subjects earned less than RM1000 per month, half of the subjects in this study had a monthly income of RM2000 to RM3000. However, some subjects in this study were still rendered below the poverty line income of RM800. ${ }^{13}$ In comparison to the 2014 mean monthly gross household income of RM4343 in Pahang, the subjects in this study had a far lower income, with a mean of RM1528, even lower than the bottom $40 \%$ of the population. ${ }^{14,15}$

Many of them relied on a variety of sources to obtain information on HIV/AIDS. This suggests that government agencies, non-government organizations, and other related groups and agencies would have to go the extra mile to combat HIV/AIDS by educating this community, for example, by organizing more health programs and workshops. A high percentage $(75.8 \%)$ of these transsexuals getting information on HIV/AIDS from health officers could indicate a good rapport between this community and the local health officers, in contrast to the report in a study from San Francisco ${ }^{16}$. Also, friends were an important source of information as well $(75.8 \%)$. Similar to other studies in Malaysia as well as in Korea, Italy, Iran, and Israel, mass media (e.g. newspapers, internet, radio, television) were sources of information on HIV/AIDS, especially television $(72.7 \%) .^{8,17-21}$ These positive indicators were encouraging, and should be stressed on, so that health education on HIV/AIDS could be promoted further from these perspectives. Besides, efforts should be made to ensure that reliable information is provided to this community, and cultural values and prejudice about HIV/AIDS and sexuality must be corrected. ${ }^{22}$

In comparison to all adults of reproductive age, transsexuals were 49 times more likely to acquire HIV infection. ${ }^{6}$ Although the majority of the subjects in this study had their HIV status tested, only 2 out of the 33 subjects were known to be HIV positive. This prevalence reported in this study was similar to that obtained from the 2012 national studies, ${ }^{1}$ however, it has been highly suspected that a large number of the HIV infection cases were under-reported, and the actual prevalence could be much higher, as shown in studies from other countries, where the prevalence could be as high as $19 \%$ to $31.9 \%$, and even $68 \% .{ }^{5,23}$ Besides, in this study, the majority of them did not test for HIV status in the most recent period, and $80 \%$ of them were unsure of their HIV status. It was not known whether they had already been infected; and if they had already been infected, the number of sex partners or customers they have had. Thus, HIV infections in transsexuals must not be missed or underdiagnosed. Transsexuals are in urgent need of HIV prevention, treatment, and medical care. ${ }^{6}$ National data showed that less than half of people living with HIV by 2013 were receiving antiretroviral therapy (ART). ${ }^{1}$ Thus, the effort for enforcing ART was still far from optimal in this country and, needless to say, the transsexual community. Furthermore, it was reported that transsexuals had lower rates of treatment adherence in comparison to other communities. ${ }^{16} \mathrm{~A}$ barrier still exists, hindering the transsexuals from accessing HIV prevention and health care services. ${ }^{24}$

The reason transsexuals in this study preferred drug intervention centers, private and government health clinics for HIV tests could be because the health care personnel in these places showed less degree of discrimination, were more friendly and sensitive in approach, and offered holistic treatment in comparison to other places. ${ }^{1,7,25,26}$

Despite the good results coming from the majority of the subjects, many of the subjects were still lacking in knowledge of HIV/AIDS. Some of the subjects were still unaware that having sex with more than one partner can increase a person's chance of being infected with HIV, some believed that there is a vaccine that could prevent HIV/AIDS, and some even believed that washing after sex can prevent HIV infection. Subjects who were unware of having an asymptomatic, HIV-positive sex partner, could place themselves at a higher risk, because they could be infected by an apparently healthylooking partner. ${ }^{27}$ Misconceptions on HIV 
transmission and other aspects of infection indicate that the subjects were not getting access to correct information on HIV infection. ${ }^{9}$ A large number of the subjects did not know about natural skin condom, but this could be because they were more familiar with latex condoms, and natural skin condom was not popular in Malaysia. Despite this, the study showed that level of education had significant associations with the level of knowledge on HIV/AIDS, as supported by studies in several parts of the world as well. ${ }^{28,29}$ This result suggests that providing education on HIV/AIDS to students at secondary and tertiary education levels is beneficial, and also emphasizes that transsexuals must not be prevented from obtaining formal education.

The overall positive attitude towards HIV infection could be because the subjects in this study were generally knowledgeable about HIV/AIDS, ${ }^{30}$ and they were living among HIV positive peers; thus, they were more accepting towards people with HIV infection, in contrast to many other studies where the subjects were normal, healthy people. ${ }^{8}$ Their negative attitude, or apathy, towards spouses with HIV infection (questions 6 and 7) could be because they were sex workers, and did not have a stable marital relationship or a fixed sexual partner. The high percentage of willingness of condom use suggested that this community was highly aware of prevention of HIV infection through condom use, and desperately need prevention programs. The higher the level of awareness of HIV/AIDS and condom use, the more they could practice safe sex. ${ }^{2}$ Majority of the subjects in this study were unsure of their HIV status, however, an extremely large number of them were keen to have their HIV status tested. This suggests that the transsexuals were still apprehensive about discrimination in HIVrelated medical services, and were hesitant or in denial to know their test results. ${ }^{2}$

\section{Limitations}

The transsexuals belonged to a marginalized population, and chose to be secluded from the society. Immense difficulties were encountered when recruitment of subjects was carried out in this population. They also showed excessive concerns about privacy because of fear of social stigma, and many of them eventually refused to give consent to participate. This rendered the sample size to only 33 subjects, and a drastic drop in the precision rate of $5 \%$ to $7 \%$ in this study.

\section{Recommendation}

Since not many studies have been done on transsexual populations, more studies in the future are highly encouraged. To obtain a more accurate result, larger scales of a similar study can be carried out. Suggestions derived from the methodology of the present study include extending the period of study, improving strategies for communication with the transsexuals so as to urge them to take part in the study, screening for HIV infection among the subjects instead of relying on self-reported HIV status, and using the HIV KQ-45 questionnaire which can assess the subjects more accurately.

Prevalence of unprotected sexual behavior, the number of lifetime sex partners, and other high risk behaviors related to HIV-infections such as injecting drug use could also be studied, as these could provide more detailed descriptions on the high risk behaviors in this population.

Besides HIV/AIDS, other sexually transmitted diseases can also be studied in this population, so that awareness of sexually transmitted diseases can be raised as a whole with HIV/AIDS within this population, and harm-reduction methods (e.g. provision of free condoms) can be employed.

During the study, it has been observed that the transsexual subjects in the present study come from a variety of social backgrounds and nationalities. It has been reported that undocumented migrants are less likely to seek medical attention, or acknowledge that they are HIV positive ${ }^{5}$. Also, transsexual sex workers from other countries did not practice safe sex, although outreach work was carried out on them as well ${ }^{2}$. Detailed socio-demographic data may be required in future studies to determine the origin of the subjects, so that education and prevention methods on HIV/AIDS can be tailored accordingly, and their psycho-social problems can be dealt with more strategically. Transsexual sex workers from foreign countries could be an important nidus for HIV transmission.

A high level of knowledge and a positive attitude towards HIV/AIDS will mean nothing if the transmission is not minimized or stopped. The needs of these transsexuals should be addressed. Intervention programs should be targeted to this population, such as regular or routine screening tests for HIV infection and providing anti-retroviral therapy to HIV positive transsexuals. More importantly, it should be emphasized that transsexual workers should be informed on the skills to negotiate for condom use with their sex partners. Treatment compliance should also be enforced on those who are eligible for and also already on antiretroviral therapy. As for health care personnel, especially doctors, the transsexual population must not be marginalized from the right of receiving medical care. Doctors and other health care personnel must be proactive in providing medical services towards these people, even if it means to serve this community down to the backstreet level. Treatment must be comprehensive and holistic, instead of disease-focused. Sensitive but dedicated and persistent approach must be used to encourage the transsexuals to seek medical help. 
Health education programs remain the main force for prevention and control of HIV infection; and, throughout history, ever since the discovery of HIV infection, strategies have been developed, refined, and improved to suit the interest of the general public, so as to educate people on the importance of HIV/AIDS. The transsexuals urged ongoing outreach, counselling, and educational programs to be carried out, together with support groups and the setup of drop-in centers ${ }^{2}$. Since the majority of the subjects in this study were Muslim, worked as sex workers, and had relatively low income, urgent attention from religious bodies and non-government organizations is needed to assist this population in terms of spirituality, employment, and financial support. However, under all circumstances, abstinence is the best way to prevent HIV transmission. Authors from this study suggest that the sex trade among transsexuals must be abolished in toto, by all means. Although transsexual sex workers constitute a small population group, they are definitely exposed to high risk situations, and have an important role in HIV transmission.

\section{CONCLUSION}

In this study, it was found that the male-to-female transsexuals in Kuantan mostly were younger adults, Muslims, and had completed secondary education. The majority of them sold sex, and earned a low income. They demonstrated good knowledge and positive attitude towards HIV/AIDS. Their level of education is significantly associated with knowledge of HIV/AIDS. Despite the positive outcome from this study, misconceptions towards HIV/AIDS still exist among this population. Transsexuals must not be deprived of formal education. The needs of transsexuals must be addressed. Education and interventions from multiple directions on HIV/AIDS are desperately needed to deliver the correct information to this population efficiently, so as to emphasize prevention, early detection, and treatment of the infection. This marginalized population also requires attention from religious bodies and non-government organizations to provide help with employment, financial, spiritual, and psycho-social issues.

\section{Acknowledgement}

Immense gratitude must be expressed to International Islamic University Malaysia for providing the resources for this study, to Mdm Mona Yap binti Abdullah from Centre for Languages and Pre-University Academic Development and Asst. Prof. Dr. Niza binti Samsuddin from the Department of Community Medicine for developing and verifying the translated questionnaire.

\section{Conflict of interest}

The authors in this study declare that there is no conflict of interest.

\section{References}

1. The Global AIDS Response Progress Report 2014, Malaysia. Ministry of Health Malaysia 2014.

2. Teh YK. HIV-related needs for safety among male-to-female transsexuals (mak nyah) in Malaysia. SAHARA J (Journal of Social Aspects of HIV/AIDS Research Alliance) 2009; 5(4):178-185.

3. Clements-Nolle K, Marx R, Guzman R, Katz M. HIV prevalence, risk behaviors, health care use, and mental health status of transgender persons: Implications for public health intervention. Am J Public Health 2001; 91(6):915.

4. Wei $\mathrm{CL}$, Baharuddin A, Abdullah R, Abdullah Z, Ern KPC. Transgenderism in Malaysia. 2012.

5. Joint United Nations Programme on HIV/AIDS (UNAIDS). The Gap Report. UNAIDS 2014.

6. Baral SD, Poteat $T$, Strömdahl S, et al. Worldwide burden of HIV in transgender women: a systematic review and meta-analysis. Lancet Infect Dis 2013; 13(3):214-222.

7. Kenagy GP. HIV among transgendered people. AIDS Care. 2002; 14(1):127-134.

8. Thanavanh B, Harun-Or-Rashid M, Kasuya $H$, Sakamoto J. Knowledge, attitudes and practices regarding HIV/AIDS among male high school students in Lao People's Democratic Republic. J Int AIDS Soc 2013; 16(1).

9. Al-Rabeei NA, Dallak AM, Al-Awadi FG. Knowledge, attitude and beliefs towards HIV/AIDS among students of health institutes in Sana'a city. East Mediterr Health J 2012; 18(3).

10. Carey MP, Schroder KE. Development and psychometric evaluation of the brief HIV Knowledge Questionnaire. AIDS Edu Prev 2002; 14(2):172.

11. Guadamuz TE, Wimonsate W, Varangrat A, et al. HIV prevalence, risk behavior, hormone use and surgical history among transgender persons in Thailand. AIDS Behav 2011; 15(3):650-658.

12. Van Devanter N, Duncan A, Raveis VH, et al. Continued sexual risk behaviour in African American and Latino male-to-female transgender adolescents living with HIV/AIDS: a case study. J AIDS Clin Res. 2011.

13. Tenth Malaysia Plan 2010-2015. The Economic Planning Unit, Prime Minister's Department, Putrajaya.2010.

14. Table 2: Mean Monthly Gross Household Income by Ethnic Group, Strata and State, Malaysia, 1970-2014. Economic Planning Unit, Prime Minister's Department, Putrajaya.

15. Table 5: Mean Monthly Gross Household Income of Top $20 \%$, Middle $40 \%$ and Bottom $40 \%$ of Households by Ethnic Group and Strata, Malaysia, 1970-2014. Economic Planning Unit, Prime Minister's Department, Putrajaya.

16. Sevelius JM, Patouhas E, Keatley JG, Johnson 
MO. Barriers and facilitators to engagement and retention in care among transgender women living with human immunodeficiency virus. Ann Behav Med 2014; 47(1):5-16.

17. Wong L-P, Chin C-KL, Low W-Y, Jaafar N. HIV/AIDS-related knowledge among Malaysian young adults: Findings from a nationwide survey. J Int AIDS Soc 2008; 10(6):148.

18. Mehra B, Bhattar S, Bhalla P, Rawat D. HIV/AIDS Awareness among VCT Clients: A Cross-Sectional Study from Delhi, India. BioMed Res Int 2014; 2014.

19. Yoo H, Lee SH, Kwon BE, Chung S, Kim S. HIV/AIDS knowledge, attitudes, related behaviors, and sources of information among Korean adolescents. J Sch Health 2005; 75(10):393-399.

20. Signorelli C, Pasquarella C, Limina RM, et al. Third Italian national survey on knowledge, attitudes, and sexual behaviour in relation to HIV/AIDS risk and the role of health education campaigns. Eur J Public Health 2006; 16(5):498-504.

21. Brook U. AIDS knowledge and attitudes of pupils attending urban high schools in Israel. Patient Educ Couns 1999; 36(3):271-278.

22. Wolffers I. Culture, media, and HIV/AIDS in Asia. The Lancet 1997; 349(9044):52-54.

23. Elifson KW, Boles J, Posey E, et al. Male transvestite prostitutes and HIV risk. Am J Pub Health 1993; 83(2):260-262.

24. Transforming Health: International Rights Based Advocacy for Trans Health. New York: Open Society Foundations; 2013

25. Melendez RM, Pinto RM. HIV prevention and primary care for transgender women in a community-based clinic. J Assoc Nurses AIDS Care 2009; 20(5):387-397.

26. Grossman AH, D'augelli AR. Transgender youth: Invisible and vulnerable. J Homosex 2006; 51(1):111-128.

27. Sarker M, Milkowski A, Slanger T, et al. The role of HIV-related knowledge and ethnicity in determining HIV risk perception and willingness to undergo HIV testing among rural women in Burkina Faso. AIDS Behav. 2005; 9(2):243-249.

28. Lui PS, Sarangapany J, Begley K, Coote K, Kishore K. Medical and Nursing Students Perceived Knowledge, Attitudes, and Practices concerning Human Immunodeficiency Virus. ISRN Public Health. 2014; 2014.

29. Haile BJ, Chambers JW, Garrison JL. Correlates of HIV knowledge and testing: Results of a 2003 South African survey. J Black Stud 2007.

30. Paul MM. The knowledge of and attitudes towards HIV/AIDS among post-secondary students in a southern Ethiopian city. 2011. 